\title{
Irrigation of Saline Lands With Activated Collector-Drainage Water Activated In The Magnetic Field
}

\author{
Mustafayev M.G. ${ }^{1, *}$, Iskenderov M.Y. ${ }^{2}$ \\ 1 Institute of Soil Science and Aqrochemistry, National Academy of Sciences of the Azerbaijan Republic; Baku, Azerbaijan. \\ 2 Azerbaijan Scientific Production Association, "Water engineering and Amelioration", Azerbaijan.
}

How to cite this paper: Mustafayev M.G., Iskenderov M.Y. (2020) Irrigation of Saline Lands With Activated Collector-Drainage Water Activated In The Magnetic Field. International Journal of the Science of Food and Agriculture, 4(1), 24-29.

DOI: $10.26855 /$ ijfsa.2020.03.005

Received: May 13, 2019

Accepted: May 30, 2019

Published: February 12, 2020

*Corresponding author: Mustfayev M. G. Institute of Soil Science and Aqrochemistry, National Academy of Sciences of the Azerbaijan Republic; Baku, Azerbaijan..

Email: meliorasiya58@mail.ru

\begin{abstract}
The issues related the results of investigations on irrigation of saline lands with collector-drainage water activated in the magnetic field, salinization at the depth of one meter till and after washing soil with sweet water, ion content of toxic salt, dynamics of mineralization degree of ground and drainage water in test and control variants are being analyzed in the article.

It is determined that, collector-drainage water activated in the magnetic field, could be used for removing toxic salt in the lands with high water permeability in Mughan steppe. Giving washing water for flushing below the rate for 2-3 times could save sweet water resources.
\end{abstract}

\section{Keywords}

Collector-drainage waters, magnetic field, water deficiency, environment, flushing, drainage

\section{Introduction}

The issues related passing irrigation water to irrigated areas after passing through magnetic fields, have been researched by a number of specialists recently. The aim was to raise the level of crop yield. They came to conclusion that it is possible to achieve raising the level of crop yield in such a way.

A number of laboratory tests have been conducted at the Institute of Design of Water Farm Objects in Moscow. The principal goal was to clean the saline lands from harmful salt. The initial results have been received successfully.

Comparative experiments related washing the saline heavy soils with perchloric acid and magnetic water have been conducted since 1973 in Volgograd Scientific and Production Union "Hydraulic \& Melioration".

The authors of the experiments came to conclusion that, it is possible to remove salt for 18-32 per cent more while washing with magnetic water, than that of washing soils with plain water. Perchloric acid solution could be successfully used.

Issues of washing of saline soils by hydrodynamic activation of water systems have neen studied by the Institute of Pedology of the National Academy of Sciences of Kazakhistan.

Experiments related irrigation of agricultural plants with magnetic water and washing of saline soils took place under A.G.Behbudov's leadership in Azerbaijan Scientific and Production Union "Hydraulic \& Melioration". A.A.Imamaliyev and M.Y.Iskenderov were the responsible executing officers.

Changing crop yield and quality of various agricultural plants while irrigating with magnetic water of the Caspian Sea, efficiency of washing saline soils with drainage water have been studied in the course of experiments. Polyvariant 
experiments related irrigation took place in Absheron peninsula in small areas, and multiple-choice probations related water flushing took place in Mughan steppe in large areas. A number of the issues have been clarified basing upon investigations and new technologies were carried out for using highly mineralized water in irrigation and water flushing. Suggestions, recommendations and methodic workbooks were elaborated and presented to corresponding organizations. Thus, as per investigations conducted in our country and abroad, toxic salt solution process improves while using magnetic waters in comparison with plain water. The lands salt desorption coefficient raises for 20-25 per cent, flushing rate reduces for 1.5-2.5 times, washing period draws in for 1.5-2.0 times and removing toxic salt from soil increases for 20-40 per cent.

Water physical and chemical properties change during magnetic water treatment. This fact was proved by a number of investigations in various conditions - laboratory and field.

Number of $\mathrm{CaCO}_{3}, \mathrm{Fe}(\mathrm{OH})_{2}$ and $\mathrm{Fe}(\mathrm{OH})_{3}$ compounds increase when water passes through magnetic field, and it causes to diminution of the mentioned compounds in natural water. Diminution of $\mathrm{CaCO}_{3}$ compounds in natural water is connected with carbon dioxide gas balance movement towards the right:

$$
\begin{gathered}
\mathrm{Ca}\left(\mathrm{HCO}_{3}\right)_{2} \rightarrow \mathrm{CaCO}_{3} \downarrow+\mathrm{CO}_{2}+\mathrm{H}_{2} \mathrm{O} \\
\mathrm{CO}_{2}+\mathrm{H}_{2} \mathrm{O} \rightarrow \mathrm{H}_{2} \mathrm{CO}_{3}
\end{gathered}
$$

As it is seen from chemical reaction, calcium carbonate $\left(\mathrm{CaCO}_{3}\right)$ in water sinks after passing through the magnetic field and concentration (density) of free carbon dioxide gas $\left(\mathrm{CO}_{2}\right)$ in the solution goes up. Then, water partly becomes "sweet" and a part of toxic salt moves to insoluble phase. At the result density growth of carbon dioxide gas $\left(\mathrm{CO}_{2}\right)$ raises water solution ability.

Inductive current is formed in the fluid and interphase while water passes through intermagnetic vacuum. Inductive current is characterized by electric conduction $(\sigma)$, water flow velocity $(v)$ and induction.

$$
\vec{J}=\sigma[\vec{v} \cdot \vec{B}]
$$

Magnetic hydrodynamic force occurs under mutual impact of induction and current:

$$
f_{\text {mag }}=\vec{J} \cdot B \text {. }
$$

Presence of such force in the fluid and interphase limits brings to formation of vertical movement and turbulent stream near small particles. Turbulence intensifies transition of molecular-dissolved gas to the vertical movement centre. At that time speedily increased gas bubbles comes off the vertical movements centre. Thus, an output of free gases increases. Water enriched with small gas bubbles breaks as soon as comes into the open space. Fluid deaeration in porous medium broadens the soil pores and increases its discharge capacity.

Activation of water systems in magnetic field as well causes to decreasing of fluid surface tension. Decreasing of surface tension accelerates exit of water-soluble air. In connection with it, ability of water solubility raises.

Use of collector-drainage water with high mineralization degree for washing saline lands becomes topical due to the experiments and theoretical points described above.

Interrelated combined tasks have been fulfilled for studying efficiency and impact of collector-drainage water (after being processed in the magnetic field) with high mineralization degree to the process of removing toxic salt from saline soils.

Test and production site was chosen taking into account the area hidrogeological condition, degree of drainage, existence of collector-drainage network, sufficiency of water resources in collector-drainage network, soils salinization degree and etc.

Lands water-physical properties were studied taking into account soil moisture, soil density, allowed water-retaining capacity, intake rate of the soil, permeability coefficient of soil cover. The bore-holes (with $4 \mathrm{~m} \mathrm{depth}$ ) were drilled in 20 observation sites before water flushing process. Earth samples from each $10 \mathrm{sm}$ and $20 \mathrm{sm}$ depth were taken and analyzed. Earth sections were put at one meter depth in 3 points of the experiment site. Earth samples were taken repeatedly twice from each $10 \mathrm{sm}$ layer. Soil moisture and soil density was determined at the result of this experiment. Quality of collector-drainage and pure water appointed for washing was determined as to their mineralization degree and other factors. Water samples taken from irrigation canal and water samples taken from collector-drainage (before and after passing the magnetic apparatus), were chemically analyzed.

YMO-1000-7.5 brand magnetic apparatus with efficiency 7200 cubic meter per hour was used for magnetizing water (treatment in the magnetic field).

Earth samples were taken from 20 experiment sites before and after washing for studying washing efficiency. Earth 
samples were taken from each $20 \mathrm{sm}$ layer till one meter depth. The samples were put to the chemical analysis. Simultaneously, the samples were taken from drainage and ground water for evaluating the drainage activity in the experiment site. The samples were put to the chemical analysis as well.

Spillways (Chipoletty type) at the end of the canals and drains have been installed for determining water volume and water rate appointed for washing. Water discharge and volume, given to the site and removed from the site, was determined due to the spillways. The notes were registered every 3 hours at day-time and every 6 hours at night-time.

Experiment and productive site was selected at the territory of Saatly district at the area of collective farm "Joyous life". Total area of the experiment site constituted 110 he. Bivariant tests with clean canal and clean collector-drainage water took place in 44 he of this area. Polyvariant tests took place at the rest part of probation area.

D-64 and D-10 subsurface drains from the north, open collector CD-7 from the south, surface water basin CD-7 from the south and surface water basin CD-7-1-1 from the east surrounded experiment area.

Grey and grey-meadow lands are met in the experiment area. Mechanical composition: heavy loams (0-1,0 meter), clay soil (1.0-2.5 meter). Sand and sandy loams interlace below 2.5 meter depth. Though the earth and ground layers possess heavy mechanical composition, their water permeability is high. Water absorption rate constituted 13 meter/day during the first hours, then 6.5 meter/day later. Filtration coefficient varies between $5.8-6.4 \mathrm{~m} /$ day.

Natural humidity-19-24 per cent in one meter depth, allowed moisture-28-31 percent, soil density-1.32-1.38 litre/cubic sm constituted in the experiment site.

Table 1 Mineralization degree and chemical analysis of water passed to washing, g/litre

\begin{tabular}{ccccccccc}
\hline Water title & $\mathrm{HCO}_{3}^{\prime}$ & $\mathrm{Cl}^{\prime}$ & $\mathrm{SO}_{4}^{\prime \prime}$ & $\mathrm{Ca}^{\prime \prime}$ & $\mathrm{Mg}^{\prime \prime}$ & $N a^{\prime}+K^{\prime}$ & $\begin{array}{c}\text { Sum of salt } \\
\text { residual }\end{array}$ \\
\hline Collector-drainage & 0,244 & 6,567 & 3,082 & 0,720 & 0,816 & 3,427 & 14,856 & 18,50 \\
\hline Canal & 0,159 & 0.177 & 0,329 & 0,140 & 0,036 & 0,102 & 0,943 & 1,08 \\
\hline
\end{tabular}

The probations have been held in 2 variants in order to determine washing efficiency and possibility of using collectordrainage water activated in the magnetic sphere for the washing process.

I variant - washing with clean collector-drainage water activated in the magnetic sphere (test)

II variant - washing with simple sweet canal water (control).

Table 2 Salinization and ion content of toxic salt in 1 meter ground layer before (numerator) and after (denominator) washing with magnetized collector-drainage water, \% (I variant)

\begin{tabular}{|c|c|c|c|c|c|c|c|}
\hline $\begin{array}{l}\text { Samples taken } \\
\text { from points № }\end{array}$ & $\mathrm{HCO}_{3}^{\prime}$ & $\mathrm{Cl}^{\prime}$ & $\mathrm{SO}_{4}^{\prime \prime}$ & $\mathrm{Ca}^{\prime \prime}$ & $\mathrm{Mg}^{\prime \prime}$ & $N a^{\prime}+K^{\prime}$ & $\begin{array}{c}\text { Dry } \\
\text { residual }\end{array}$ \\
\hline \multirow{2}{*}{1} & 0,025 & 0,063 & 0,210 & 0,072 & 0,027 & 0,494 & 1,922 \\
\hline & $\overline{0,026}$ & $\overline{0,038}$ & $\overline{0,220}$ & $\overline{0,046}$ & $\overline{0,023}$ & $\overline{0,271}$ & $\overline{0,976}$ \\
\hline \multirow{2}{*}{2} & 0,030 & $\underline{0,052}$ & 0,688 & $\underline{0,054}$ & 0,027 & 0,453 & 1,312 \\
\hline & $\overline{0,031}$ & 0,255 & 0,220 & $\overline{0,020}$ & $\overline{0,015}$ & 0,221 & $\overline{0,743}$ \\
\hline \multirow{2}{*}{3} & 0,027 & 0,209 & 0,909 & 0,048 & 0,039 & 0,396 & 1,502 \\
\hline & $\overline{0,030}$ & $\overline{0,460}$ & $\overline{0,370}$ & $\overline{0,080}$ & $\overline{0,040}$ & $\overline{0,315}$ & $\overline{1,354}$ \\
\hline \multirow{2}{*}{4} & 0,018 & 0,783 & 0,891 & 0,124 & 0,073 & 0,653 & 2,220 \\
\hline & 0,040 & 0,192 & 0,240 & 0,026 & 0,013 & 0,203 & 0,717 \\
\hline \multirow{2}{*}{5} & 0,021 & $\underline{0,655}$ & 0,448 & 0,087 & 0,052 & 0,446 & 1,773 \\
\hline & 0,052 & $\overline{0,071}$ & $\overline{0,320}$ & 0,030 & $\overline{0,001}$ & 0,158 & 0,628 \\
\hline
\end{tabular}

Ground water is met at 1.5-3.0 meter depth from the earth surface and mineralization degree varies between 6-85 g/litre. 
As per full chemical analysis of the earth samples, taken before the washing, the soils in the experiment area were subjected to severe salinization. Average salinization degree is over 2 per cent as per dry residual. The salinization is characterized by chloride-sylphate-natrium type.

Mineralization degree and chemical analysis of collector-drainage and canal water passed to washing is given at the table 1 .

The washing was realized in two variants and in two stages simultaneously (in autumn and spring). At each stage 3000 cubic meter/he flushing water was given to the areas. After a certain interval flushing water was given to the experiment and control sites. After water flushing completion, earth samples were taken from marked points at each 20 sm interval till 2.5 meter depth. Taken earth samples were analyzed. The chemical analysis results are presented at the table 2 .

Salinization in one meter depth falls from $2,056 \%$ to $0,658 \%$ at the result of washing with collector-drainage water. Salinization falls from $2,041 \%$ to $0,957 \%$ at the result of washing with canal water. Amount of chlorine-ion reduced for 4,4 times, amount of sylphate-ion reduced for 2,8 times in the probation variant. Amount of chlorine-ion reduced for 2,7 times, amount of sylphate-ion reduced for 2 times in the control variant.

Amount of hydrocarbonate $\left(\mathrm{HCO}_{3}\right)$ approximately increased twice in the probation variant during washing process. The amount of hydrocarbonate became invariable in the control variant. Increase the amount of hydrocarbonate ion is explained by the fact, that thickness of carboxylic acid $\left(\mathrm{H}_{2} \mathrm{CO}_{3}\right)$ grows, when water system is being treated in the magnetic field.

Analysis of experiment materials show that, impact of magnetized water to salt desorption process sharply falls when water is moving away from magnetic apparatus. At the distance of $150 \mathrm{~m}$ from magnetic apparatus, in one meter depth of the earth layer (sample taken from the point \#10), the salinization falls from $1,983 \%$ to $0,264 \%$ as per dry residual. At the distance of $450 \mathrm{~m}$ from magnetic apparatus, (sample taken from the point \#7), the salinization falls from $2,317 \%$ to $0,854 \%$.

It was determined that, water magnetizing activity speedily reduces by moving away from magnetizing source. This process could be explained by two facts. Firstly, speedily decompose of carboxylic gas $\left(\mathrm{CO}_{2}\right)$ from magnetic water. The second, residuum of carboxylic gas has an inverse reaction with water and calcium and turns into the salt of calcium bicarbonate $\left[\mathrm{Ca}\left(\mathrm{HCO}_{3}\right)_{2}\right]$.

Table 3 Salinization and ion content of toxic salt in 1 meter ground layer before (numerator) and after (denominator) washing with sweet canal water, \% (II variant)

\begin{tabular}{|c|c|c|c|c|c|c|c|}
\hline $\begin{array}{l}\text { Samples taken } \\
\text { from points № }\end{array}$ & $\mathrm{HCO}_{3}^{\prime}$ & $\mathrm{Cl}^{\prime}$ & $\mathrm{SO}_{4}^{\prime \prime}$ & $\mathrm{Ca}^{\prime \prime}$ & $\mathrm{Mg}^{\prime \prime}$ & $N a^{\prime}+K^{\prime}$ & $\begin{array}{l}\text { Dry } \\
\text { residual }\end{array}$ \\
\hline \multirow[b]{2}{*}{1} & 0,036 & 0,053 & 0,608 & 0,052 & 0,011 & 0,250 & 1,090 \\
\hline & $\overline{0,026}$ & $\overline{0,035}$ & $\overline{0,452}$ & $\overline{0,010}$ & $\overline{0,010}$ & $\overline{0,158}$ & $\overline{0,700}$ \\
\hline \multirow{2}{*}{2} & 0,020 & 0,139 & 1,651 & 0,105 & 0,034 & 0,697 & 2,558 \\
\hline & $\overline{0,023}$ & $\overline{0,051}$ & $\overline{0,724}$ & $\overline{0,071}$ & $\overline{0,057}$ & $\overline{0,487}$ & $\overline{1,413}$ \\
\hline \multirow{2}{*}{3} & 0,024 & 0,515 & 0,811 & 0,089 & 0,049 & 0,532 & 2,108 \\
\hline & $\overline{0,018}$ & $\overline{0,208}$ & $\overline{0,423}$ & $\overline{0,076}$ & $\overline{0,034}$ & $\overline{0,217}$ & $\overline{1,027}$ \\
\hline \multirow{2}{*}{4} & 0,028 & 0,362 & 0,785 & 0,084 & 0,055 & 0,387 & 1,798 \\
\hline & $\overline{0,018}$ & $\overline{0,205}$ & $\overline{0,479}$ & $\overline{0,057}$ & $\overline{0,058}$ & $\overline{0,198}$ & $\overline{1,040}$ \\
\hline \multirow{2}{*}{5} & 0,026 & 0,559 & 1,301 & 0,158 & 0,071 & 0,704 & 2,898 \\
\hline & $\overline{0,023}$ & $\overline{0,278}$ & $\overline{0,556}$ & $\overline{0,101}$ & $\overline{0,043}$ & $\overline{0,420}$ & $\overline{1,421}$ \\
\hline
\end{tabular}

As per analysis, amount of toxic salt wasn't removed from the ground layer till allowed limit in both variants. Factual salt desorption coefficient of the soil was determined. Volobuyev's formula and actual data got from the washing results have been used for this purpose:

$$
\alpha=\frac{N}{10^{4} \cdot \lg \left(S_{0} / S\right)},
$$

Here, $\mathrm{N}$ - water rate given to washing, $\mathrm{m}^{3} / \mathrm{he}, \mathrm{S}_{0}$ - salinization degree in one meter depth of the ground layer, $\% ; S-$ salinization after washing, $\%$. 
The initial salinization was $\mathrm{S}_{0}=2,041 \% \quad$ while washing with the clean water, after washing it constituted $\mathrm{S}=0,957 \%$. $10000 \mathrm{~m}^{3} / \mathrm{he}$ water was given to the washing. As per the factual values, the soil salt desorption coefficient is given below

$$
\alpha=\frac{10000}{10^{4} \lg (2,041 / 0,957)}=3,33
$$

Allowed limit of salinization in chloride-sylphate type of lands should be till $0,4 \%$ according to the estimation criteria. Washing rate here should be as follows

$$
N=10^{4} \cdot 3,33 \lg \frac{2,041}{0,6}=17650 \mathrm{~m}^{3} / \text { he }
$$

It is interesting that during washing with collector-drainage water, the water was used for 1,7 times less in comparison with required water rate. It became possible to reduce salinization till allowed limit.

Washing efficiency was studied due to change of ground and drainage water minaralization degree as well.

Analysis of ground water samples, taken before and after washing was given in the table 4 .

As it is seen from the table, ground water mineralization degree became invariable while washing with magnitized collector-drainage water. This change was very few. Ground water average mineralization degree constituted 22,54 $\mathrm{g} /$ litre before washing, mineralization degree made $18,1 \mathrm{~g} /$ litre after washing in the experiment site.

During washing with plain clean canal water ground water mineralization degreereduced for 1,7 times in comparison with the initial state. Ground water average mineralization degree constituted $22,97 \mathrm{~g} /$ litre before washing, mineralizaton degree made $13,56 \mathrm{~g} /$ litre after washing.

\begin{tabular}{|c|c|c|c|c|c|}
\hline \multirow[t]{2}{*}{$\begin{array}{l}\text { Boreholes } \\
\quad №\end{array}$} & \multicolumn{2}{|c|}{$\begin{array}{c}\text { Washing with magnitized } \\
\text { collector-drainage water (experiment } \\
\text { variant) }\end{array}$} & \multirow[t]{2}{*}{ № of boreholes } & \multicolumn{2}{|c|}{$\begin{array}{l}\text { Washing with simple canal water } \\
\text { (control variant) }\end{array}$} \\
\hline & before washing & after washing & & before washing & after washing \\
\hline 1 & 0,58 & 1,44 & 8 & 29,40 & 3,74 \\
\hline 2 & 1,20 & 2,90 & 9 & 55,84 & 26,34 \\
\hline 3 & 13,12 & 16,80 & 10 & 27,54 & 8,34 \\
\hline 4 & 10,50 & 8,05 & 11 & 17,38 & 16,56 \\
\hline 5 & 12,05 & 10,07 & 12 & 3.16 & 4,98 \\
\hline 6 & 53,78 & 29,78 & 13 & 0,92 & 2,00 \\
\hline 7 & 44,00 & 39,60 & 14 & 26,54 & 22,96 \\
\hline average & 22,54 & 18,10 & Orta & 22,97 & 13,56 \\
\hline
\end{tabular}

Table 4 Change of ground water mineralization degree in experiment and control sites, g/litre

Change of ground water mineralization degree during washing and after washing process is associated with infiltration rate and transported salt amount. As since canal water possesses weak mineralization degree, so, ground water cleanses better. As since collector-drainage water posseses high mineralization degree, thus, ground water cleanses weakly. Inverse impression is observed while studying drainage water mineralization degree. Thus, in experiment variant drainage water mineralization degree in the washing process was high, but, drainage water mineralization degree was few in the control variant.

Table 5 Dynamics of drainage water mineralization degree, g/litre

\begin{tabular}{cccccc}
\hline \multirow{3}{*}{ Variants } & \multirow{3}{*}{ Drains titles } & \multicolumn{4}{c}{ Time of taking samples } \\
\cline { 3 - 6 } & & \multicolumn{3}{c}{ Experiment } & \multicolumn{3}{c}{ Control } \\
\cline { 3 - 6 } & & 10. XII.83 & 25. II.84 & 29. III.84 & 6. IV.84 \\
\hline I & 18,50 & 36,10 & 26,16 & 23,48 \\
\hline
\end{tabular}




\begin{tabular}{llllll} 
II & D - 63 & 17,98 & 25,15 & 22,23 & 19,50 \\
\hline
\end{tabular}

Mineralization degree of the drainage serving to the area being washed with magnetized collector-drainage water increased more than 2 times during the washing process. Mineralization degree of the drainage water serving to the area being washed with clean canal water increased for 1,4 times. Mineralization degree of the drainage water began to reduce gradually in the following stages.

Thus, as to experimental investigations, collector-drainage water activated in the magnetic field could be used for removing toxic salt from high water permeable lands in Mughan steppe. At that time the area natural or artificial drainage degree should be provided properly. Allocating the water for washing for 2-3 times below the rate, might save a great deal of sweet water resources.

\section{Summary}

1. Thus, as per experimental information, collector-drainage water being activated in the magnetic field, could be used for water flushing of the lands with good water permeability.

2. The area's natural and artificial drain degree should be provided fully while using water flushing with magnetic water.

3. It was determined that collector-drainage water with $18,5 \mathrm{~g} /$ litre mineralization degree could be used for water flushing only after being activated in the magnetic field. Such water corresponds to water flushing of saline lands with good water permeability.

\section{References}

[1] Behbudov A.K., Imamverdiyev A.A., Iskenderov M.Y. Recommendations for using mineralized magnetized water for washing and irrigation in the North Mughan/ NTO Az.Sc.Prod.As."Water Eng.and Amel", 1982-1984, p.146-154.

[2] Bondarenko N.F., Gak E.Z. Changing properties of natural waters in the magnetic fields. Lectures of Vasnkhil, 1979, issue 5, p.36-38.

[3] 3. Bondarenko N.F., Gak E.Z., Gak M.Z., Rekhinson E.E. On changing the character of hydrodynamic cavitation in nonhomogeneous magnetic field, IFJ, 1978, T.35 № 5, p.843-850.

[4] 4. Yakovlev N.P., Litvinova A.D. Applying magnetic water for soils washing. Newsletter of the Institute named after Dokuchayev, M.1977, issue 15, p.37-41.

[5] 5. Bondarenko N.F., Gak E.Z., Rekhinson E.E. Applying magnetic fields for saline soils washing, Herald Agricultural Science, 1976, №2.

[6] 6. Magnetic treatment of water systems. Thesis of lectures of IV national conference. M.1981, p.137-150.

[7] 7. Imamverdiyev A.A. Efficiency of using drainage and sea-water for washing and irrigating high permeable soils. Abstract of a thesis of the candidate of technical sciences, Baku, 1985, p.22. 